\title{
次元削減による多項関係予測
}

\section{A Dimension Reduction Approach to Multinomial Relation Prediction}

\author{
則 の光み \\ ボレガラ \\ Danushka Bollegala \\ 鹿島 久嗣
}

カーネギーメロン大学

Carnegie Mellon University

nozomi.noriegmail.com

リヴァプール大学

University of Liverpool

danushka.bollegala@liverpool.ac.uk

東京大学 / JST さきがけ「知の創生と情報社会」研究領域

The University of Tokyo / JST PRESTO

kashima@mist.i.u-tokyo.ac.jp

keywords: graph, dimension reduction, social media, user modeling, eigenvalue problem

\begin{abstract}
Summary
Many phenomena in the real world can be represented as multinomial relations, which involve multiple and heterogeneous objects. For instance, in social media, users' various actions such as adding annotations to web resources or sharing news with their friends can be represented by multinomial relations which involve multiple and heterogeneous objects such as users, documents, keywords and locations. Predicting multinomial relations would improve many fundamental applications in various domains such as online marketing, social media analyses and drug development. However, the high-dimensional property of such multinomial relations poses one fundamental challenge, that is, predicting multinomial relations with only a limited amount of data. In this paper, we propose a new multinomial relation prediction method, which is robust to data sparsity. We transform each instance of a multinomial relation into a set of binomial relations between the objects and the multinomial relation of the involved objects. We then apply an extension of a low-dimensional embedding technique to these binomial relations, which results in a generalized eigenvalue problem guaranteeing global optimal solutions. We also incorporate attribute information as side information to address the "cold start"problem in multinomial relation prediction. Experiments with various real-world social web service datasets demonstrate that the proposed method is more robust against data sparseness as compared to several existing methods, which can only find sub-optimal solutions.
\end{abstract}

\section{1.は じめに}

\section{$1 \cdot 1$ 多項関係予測の重要性}

データ解析技術の潮流は, 個々のデータを対象とした 解析から，データ間の関係の解析に移行しつつあると言 える. 通常のデータ解析では一つのデータについて成り 立つ性質を推論するが , データ間の関係の解析ではデー タの組 (関係データ) について, 兴の間に成立する関係の 有無や，関係のもつ性質についての推論を行う. 関係デー タの解析はオンラインマーケティング (顧客と商品の間の 購買, 評価等の関係) , 創薬スクリーニング (薬刘と標的 の間の関係) , ソーシャルネットワーク解析 (Facebook , Twitter 等における人間関係) など樣々な分野で行われて おり, データ間の関係に注目することで, 個々のデータ に注目しているだけでは見えない性質を捉えることがで きると期待されている .

関係データの中でも最もシンプルなものは, 二項関係 のデータである .これは二つのオブジェクトの間に特定
の関係が成立するかの有無や，弚の関係の強さについて 表現したデータであり, グラフや行列などを用いて容易 に表現することができる．ここで，オブジェクトを“関 係を構成する，一単位として扱われるデータ”として定義 する . 近年は , 二つのオブジェクト間に限らず , 三つ以 上の複数のオブジェクト間に生じる“多項関係”に対する 解析が盛んである．本論文で定義する多項関係とは“複 数種類, 複数個のオブジェクト間に生じる一種類の関係” である . 例えば , ユーザー $A$ が Web 上のリソース $B$ に 対してあるタグ $C$ を付けた行為は, (ユーザー $A$, リソー ス $B$ ，タグ $C$ ) という三種類 , 三個のオブジェクトの間 に生じる一種類（タグ付け）の関係なので, 多項関係で ある*1. 多項関係の解析方法は樣々あるが, 近年盛んに 研究されているのがテンソル [Kolda 09] を用いた方法で

\footnotetext{
*1 また, 自然言語処理における述語項構造解析に関連付けて述 べると，本論文か対象とする多項関係は，述語 (predicate) が一 種類で, 項 (argument) が複数種類 , 複数個にわたる述語項構造 を対象としているとも言える
} 
ある . 例えば経時変化するソーシャルネットワークでは， 人と人の間の二項関係に対して，光の関係がいつ生じた のかという時間情報が加わり三項関係となるが，このよ うな経時変化するネットワークにおける解析は, リンク 予測 [Dunlavy 11]や異常検知 [Koutra 12] などのタスク でテンソルを用いて行われている. 弚の他，センサース トリームのデータ解析では (時間 , 場所 , センサーデー タの型) の三項関係 [Sun 06a] に対して, ウェブのハイ パーリンクの解析では (リンク元ページ，リンク先ペー ジ，アンカーテキスト) の三項関係 [Kolda 05] に対して， インターネットのトラフィック解析では (送信元 IP , 送 信先 IP , ポートナンバー，時間) の四項関係 [Sun 06b] に対して，弚れ攵れテンソルを用いた解析が行われてい る.現実のデータに見られるこのような高次の関係 (多 項関係) を活用することで, 二項の関係に注目している だけでは見えない性質を捉えることができると期待され ている。

多種多樣な情報源からのデータを統合した解析の重要 性か増す中，データ間の高次の関係を捉える多項関係の 解析技術は今後益々求められるようになると考えられる。 本論文では, とりわけ直接的に意思決定に結びつく予測 問題に着目し，多項関係の予測問題を扱う.

\section{$1 \cdot 2$ 多項関係予測の課題: データ疎性}

多項関係予測の重要性は今後増していくと考えられる が, 多項関係の予測においては，観測データの疎性に対 して頑強な予測を行うことが課題となる. 関係データで 生じる観測データの疎性の問題とは, 関係に含まれる才 ブジェクト数の増加に伴い, 可能な関係の組みわせの数 か指数的に増えるため, 実際に観測される関係の数が, 可 能な場合の数に対して相対的に小さくなるために生じる ものである.例えば，Cai らの報告によると，広く使用さ れているソーシャルブックマークサービスのデータセッ 卜では, 可能な組み合わせに対して $0.01 \%$ 程度の関係し か観測されていなかった . また，ほとんどのオブジェク 卜は少数の関係にしか関与せず, 弚の分布はべき乗分布 に従っていた [Cai 11] . 後者の疎性は，推薦タスクにお いて重要な問題と見なされているコールドスタート問題 [Schein 02] と呼ばれる状況でしばしば遭遇するものであ る.これは, ユーザーの過去の行動履歴の情報から推薦 を行うシステムにおいて, 新規ユーザー (新規アイテム) など , 紐付けられる行動履歴の情報か限られたユーザー (アイテム) に対する推薦を行うのか難しくなる問題であ る.現実の関係データはこのような踈性を示すと考えら れるので, このような踈性に対応した予測手法が必要と なる。

近年では, 多項関係予測を行うにあたってテンソル分解 の手法 [Kolda 09, Dunlavy 11, Koutra 12, Sun 06a, Kolda 05, Sun 06b, Symeonidis 08, Rendle 09, Rendle 10] がし ばしば利用されているが, 多くの手法は非凸最適化問題
として定式化されるため，特にデータが疎である場合に は局所解による精度悪化か問題となる.近年では凸最適 問題として定式化する試みも行われてはいるが,やはり 固有値問題を繰り返し解く必要があるため, 計算か煩雑 になるという問題が存在する .

\section{$1 \cdot 3$ 提案手法の概要: 二項関係への変換, 次元削減, 属} 性情報の活用

本論文では, データ踈性に対して頑強であり,かつ, 固 有值問題を一度解くだけで大域解を得ることができる，多 項関係予測のための手法を提案する . 我々の提案手法は (1) 多項関係から二項関係の集合への变換，および, 弚れ ら二項関係集合の低次元空間への埋め込みにより，大域 解を保証する最適化問題としての定式化，(2)末観測の才 ブジェクトが多数存在する場合でも頑強な予測を行うた めの, オブジェクト属性の活用という二つのアイデアに 基づいている.

まず， $K$ 個のオブジェクトを巻き込む関係を，各才 ブジェクトと，光のオブジェクトを巻き込む関係インス タンスの間の $K$ 個の二項関係に変換する .ここで, 関 係インスタンスは“オブジェクト間に生じた関係光れ自 体を一単位としたデータ”と定義する。图 1 に，(花子 ，Www.ai-gakkai.or.jp，太郎)の間の多項関係 を, 関係インスタンスと, “花子” , “ ai-gakkai.or.jp” , “ 太郎”の三つのオブジェクトの間の二項関係の集合に変 換した例を示す .このような変換はハイパーグラフの接 続行列 [Voloshin 09] に相当する．続いて，上記の変換 で得られた二項関係の集合に対して，非線形次元削減手 法 [Belkin 03] を適用することで，各オブジェクトと光の オブジェクトが参加した関係インスタンスが潜在空間で 近傍に位置するような潜在空間への写像を学習し, 異種 のオブジェクトを共通の潜在空間に埋め込む . 結果とし て得られる最適化問題は, 大域解を保証する一般化固有 值問題として定式化されるため, データ踈性に対して頑 強な予測が可能となる．加えて，多項関係予測における コールドスタート問題に対処するために，異種オブジェ クトの樣々な属性を活用する . 例えば，オブジェクトと してユーザを考えると, ユーザは, 年齢, 性別, 所属な どで表現することができるだろう .このようなオブジェ クトの属性は, ほとんどのオブジェクトが僅かな関係に しか関与しないような状況では予測に有用であると期待 できる .

我々は，提案手法の頑強性を評価するために，現実の データセットとして , ソーシャルメディア上でのユーザー の行動データを用いて実験を行った . 結果, 提案手法は, (1) 訓練時に少数の関係データしか得られない状況や，(2) 予測時に大量の未知のオブジェクトが存在するような状 況といった , データの疎性が顕著な゙状況下で, 標準的な テンソル分解手法を予測精度で上回り，データが疎な状 況でも安定した予測精度を実現した。 


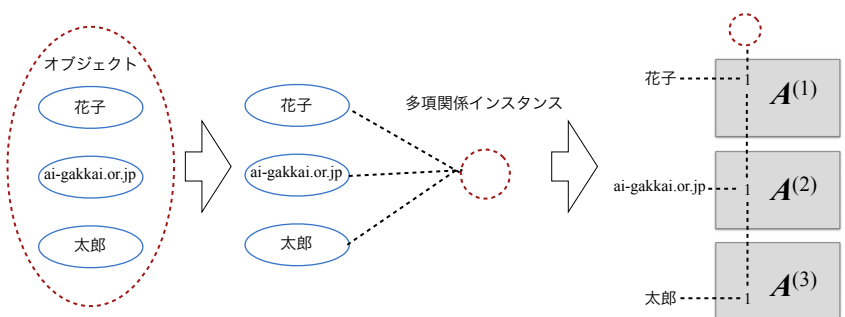

図 1 三種類 $(K=3)$ のオブジェクトを巻き込む一つの多項関係を 三つの二項関係に変換し, 更に弚れらが, 接続行列における 要素として表現されることを示す例 .

\section{2. 提 案 手 法}

\section{$\mathbf{2} \cdot \mathbf{1}$ 問 題 設 定}

人や Web ページなど , 異なる種類のオブジェクトの 間で，ある特定の種類の関係がどれくらい生じやす光 うかを，いくつかの観測された関係データを元に推定 する問題を考える . 例えば，ある人が，別の誰かから薦 められた Web ページを気に入るかを予測する状況を考 えてみよう.ここでの目標は, “person 1 が person 2 によって薦められた URL で指定される Web ページを気 に入る”という関係が, $\left(\right.$ person $_{1}, \mathrm{URL}$, person $\left._{2}\right)$ の 各組み合わせについてどれくらい生じやすいかを( 花子 ，www.ai-gakkai.or.jp，太郎）などの既知の事 実を元に予測することである．

$K$ 種類のオブジェクト集合， $S^{(1)}, S^{(2)}, \ldots, S^{(K)}$ があ り，弚れ帒れの集合が $N^{(k)}(1 \leq k \leq K)$ 個の才ブジェク

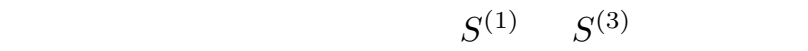
ユーザの集合に， $S^{(2)}$ をURL の集合として取ることが できる.$i$ 番目のオブジェクト $s^{(k, i)} \in S^{(k)}$ を,$s^{(k, i)}$ の ように記載する。例えば， $s^{(1,1)}$ によって花子を表す．ま た， $M$ 個の観測された関係インスタンスから成る集合， $O \subset S^{(1)} \times S^{(2)} \times \cdots \times S^{(K)}$ が得られているとする . 各 関係インスタンスは, ある特定の関係 (例えば先の例で は，気に入るという関係) がオブジェクトの特定の組み 合わせに対して成立していることを示している。例えば， $o^{(1)} \in O$ は(花子, www.ai-gakkai.or.jp, 太郎 )などである。

さて，我々の目標はオブジェクトの各組み合わせの中 で，観測された関係インスタンスの集合 $O$ に含まれてい ないものについて, 特定の関係がどれくらい生じやすい かを予測することである .

多くの現実的な状況では, 各オブジェクトは自身に関 する何かしらの情報を有する . 例えば , 人であれば年齢 や性別などのデモグラフィックな情報を持つと期待でき る.したがって,$s^{(k, i)}$ に対して,$D^{(k)}$ 次元の属性べク トル $\boldsymbol{x}^{(k, i)}$ を関連付け, 各 $k=1,2, \ldots, K$ について , ま とめて計画行列

$$
\boldsymbol{\Phi}^{(k)} \equiv\left(\boldsymbol{x}^{(k, 1)}, \boldsymbol{x}^{(k, 2)}, \ldots, \boldsymbol{x}^{\left(k, N^{(k)}\right)}\right)^{\top}
$$

とする
本論文が提案する多項関係予測の問題は, 以下のよう な入出力を持つ問題として要約できる．

問題: 多項関係予測

- 入力:

- $S^{(1)}, S^{(2)}, \ldots, S^{(K)}: K$ 種類のオブジェクト集合 - $O\left(\subset S^{(1)} \times S^{(2)} \times \cdots \times \ldots S^{(K)}\right)$ : 観測された $M$ 個の関係インスタンスから成る集合 - $\boldsymbol{\Phi}^{(1)}, \boldsymbol{\Phi}^{(2)}, \ldots, \boldsymbol{\Phi}^{(K)}:$ オブジェクトの属性を表現す る $K$ 個の計画行列

・出力: $O$ に含まれない，すなわち， $\left(S^{(1)} \times S^{(2)} \times\right.$ $\left.\cdots \times \ldots S^{(K)}\right) \backslash O$ に含まれるオブジェクトの組み合 わせに対して , 関係の生じやすさを表すスコア .

\section{$2 \cdot 2$ 次元削減を用いた多項関係予測}

ここでは, 次元削減手法を用いて，一般化固有値問題 を一度解くだけで大域解が求まる, 新しい多項関係予測 手法を提案する．まず，オブジェクトの属性を考慮しな い場合から考える 。

大域解を保証するための最初のキーアイデアは, 多項関 係を二項関係に変換することである.$K$ 種類のオブジェ

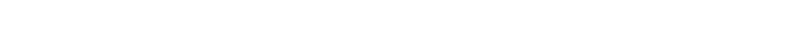
部で $K$ 個の行列を得る .これらの行列は“オブジェクト と関係インスタンスの間の関係”を表現するものである . 行列の各要素は，ある特定の才ブジェクトが，ある特定 の関係インスタンスに参加しているかを示している .

$\boldsymbol{A}^{(k)}$ を， $S^{(k)}$ に属するオブジェクトの，Oに属する関 係インスタンスに対する参加情報をまとめた $N^{(k)} \times M$ の二值行列とする. $\boldsymbol{A}^{(k)}$ の各要素 $\left[\boldsymbol{A}^{(k)}\right]_{n, m}$ は, 以下の ように定義される．

$\left[\boldsymbol{A}^{(k)}\right]_{n, m} \equiv \begin{cases}1 & \left(s^{(k, n)} \in S^{(k)} \text { が } o^{(m)} \in O \text { に参加する場合 }\right) \\ 0 & \text { (弚うでない場合). }\end{cases}$

图 1 にこの変換の例を示している.

我々の二つ目のキーアイデアは， $K$ 個の行列によって 表現された二項関係を低次元へ埋め込むことである．次 元削減を用いた二部グラフ予測の手法 [Yamanishi 09] と 似たアイデアを用いて，各オブジェクトと光のオブジェ クトが参加した関係インスタンスが潜在空間で近傍に位 置するような゙潜在空間への写像を学習し, 異種のオブジェ クトと関係インスタンスを共通の潜在次元に埋め込む．

まず最初に一次元の潜在空間への埋め込みを考えて みよう.サイズ $N^{(1)}$ のオブジェクト集合 $S^{(1)}$ は，長 さ $N^{(1)}$ のベクトル $f^{(1)}$ として埋め込まれる . 同樣にし て, 各オブジェクト集合 $S^{(2)}, S^{(2)}, \ldots, S^{(K)}$ は, 光れ艺 れ $\boldsymbol{f}^{(2)}, \boldsymbol{f}^{(3)}, \ldots, \boldsymbol{f}^{(K)}$ として埋め込まれる.サイズ $M$ の観測された関係インスタンスの集合 $O$ もまた，同じ一 次元の潜在空間に，長さ $M$ のベクトル $\bar{f}$ として埋め込 まれる . 
もし，あるオブジェクト $s^{(k, n)} \in S^{(k)}$ が，ある関係イ ンスタンス $o^{(m)} \in O$ に参加するならば，両者の埋め込 み先, $\left[\boldsymbol{f}^{(k)}\right]_{n}$ と $[\overline{\boldsymbol{f}}]_{m}$ を近くすること，すなわち，ユー クリッド距離 $\left(\left[\boldsymbol{f}^{(k)}\right]_{n}-[\overline{\boldsymbol{f}}]_{m}\right)^{2}$ を小さくすることを試み よう.このとき, 最終的に最小化すべき目的関数は以下 のように定義される .

$$
\begin{aligned}
& J\left(\left\{\boldsymbol{f}^{(k)}\right\}_{k=1}^{K}, \overline{\boldsymbol{f}}\right) \\
& \quad=\sum_{k} \sum_{i} \sum_{j}\left[\boldsymbol{A}^{(k)}\right]_{i, j}\left(\left[\boldsymbol{f}^{(k)}\right]_{i}-[\overline{\boldsymbol{f}}]_{j}\right)^{2} \\
& \quad=\sum_{k}\left(\boldsymbol{f}^{(k)^{\top}} \boldsymbol{D}^{(k)} \boldsymbol{f}^{(k)}+\overline{\boldsymbol{f}}^{\top} \overline{\boldsymbol{f}}-2 \boldsymbol{f}^{(k)^{\top}} \boldsymbol{A}^{(k)} \overline{\boldsymbol{f}}\right),
\end{aligned}
$$

ここで, $\boldsymbol{D}^{(k)}$ は, 乥の $(i, i)$ 番目の要素が $\left[\boldsymbol{D}^{(k)}\right]_{i, i} \equiv$ $\sum_{j}\left[\boldsymbol{A}^{(k)}\right]_{i, j}$ ，すなわち，オブジェクト $s^{(k, i)}$ が参加した 関係の数として定義される対角行列である .ここで, 各 $j$ について $\sum_{i}\left[\boldsymbol{A}^{(k)}\right]_{i, j}=1$ が成立することを用いた .

この目的関数は, $\boldsymbol{f}^{(k)} \equiv \mathbf{0}$ かつ $\overline{\boldsymbol{f}} \equiv \mathbf{0}$ とすることで容 易に最小化できてしまうので，このような望ましくない 解を避けるために，以下のスケーリング制約を加える．

$$
\sum_{k=1}^{K} \boldsymbol{f}^{(k)^{\top}} \boldsymbol{D}^{(k)} \boldsymbol{f}^{(k)}=1 .
$$

目的関数 (1)の $\bar{f}$ に関する最小值は $\frac{\partial J}{\partial f}=0$ とおいて 以下のように得られる.

$$
\overline{\boldsymbol{f}}=\frac{1}{K} \sum_{k=1}^{K} \boldsymbol{A}^{(k)^{\top}} \boldsymbol{f}^{(k)} .
$$

式（3）を式(1)の正負を逆転させたものに代入するこ とで, 以下の最大化問題を得る .

$$
\begin{aligned}
- & J\left(\left\{\boldsymbol{f}^{(k)}\right\}_{k=1}^{K}\right) \\
& =\frac{1}{K} \sum_{k, \ell=1}^{K} \boldsymbol{f}^{(k)^{\top}} \boldsymbol{A}^{(k)} \boldsymbol{A}^{(\ell)^{\top}} \boldsymbol{f}^{(\ell)}-\sum_{k=1}^{K} \boldsymbol{f}^{(k)^{\top}} \boldsymbol{D}^{(k)} \boldsymbol{f}^{(k)} .
\end{aligned}
$$

ゆえに，

$$
\begin{aligned}
& L\left(\left\{\boldsymbol{f}^{(k)}\right\}_{k=1}^{K}, \lambda\right)= \\
& \quad-J\left(\left\{\boldsymbol{f}^{(k)}\right\}_{k=1}^{K}\right)-\lambda\left(\sum_{k=1}^{K} \boldsymbol{f}^{(k)^{\top}} \boldsymbol{D}^{(k)} \boldsymbol{f}^{(k)}-1\right),
\end{aligned}
$$

として定義されるラグランジュ関数を $, \frac{\partial L}{\partial \boldsymbol{f}^{(k)}}=0, \frac{\partial L}{\partial \lambda}=0$ とおいて最大化することで以下を得る .

$$
\sum_{\ell} \boldsymbol{A}^{(k)} \boldsymbol{A}^{(\ell)^{\top}} \boldsymbol{f}^{(\ell)}=K(\lambda+1) \boldsymbol{D}^{(k)} \boldsymbol{f}^{(k)} .
$$

さらに, $\tilde{\lambda} \equiv K(\lambda+1)$ とすることで, 以下の一般化固 有值問題を得ることができる.

$$
\boldsymbol{A} \boldsymbol{A}^{\top} \boldsymbol{f}=\tilde{\lambda} \boldsymbol{D} \boldsymbol{f}
$$

ここで， $A, D$ と $f$ は以下のように定義される.

$$
\begin{aligned}
\boldsymbol{A} & \equiv\left[\begin{array}{c}
\boldsymbol{A}^{(1)} \\
\boldsymbol{A}^{(2)} \\
\vdots \\
\boldsymbol{A}^{(K)}
\end{array}\right] \\
\boldsymbol{D} & \equiv\left[\begin{array}{ccc}
\boldsymbol{D}^{(1)} & & \mathbf{0} \\
& \ddots & \\
\mathbf{0} & & \boldsymbol{D}^{(K)}
\end{array}\right] \\
\boldsymbol{f} & \equiv\left(\boldsymbol{f}^{(1)^{\top}}, \boldsymbol{f}^{(2)^{\top}}, \ldots, \boldsymbol{f}^{(K)^{\top}}\right)^{\top} .
\end{aligned}
$$

最大固有值に対応する固有ベクトル $f$ が, オブジェク トの，一次元空間での最適な埋め込み先である.$R$ 次元 の空間における埋め込み先 $\boldsymbol{f}_{1}, \boldsymbol{f}_{2}, \ldots, \boldsymbol{f}_{R}$ を得るために は, 固有值の大きい順に上位 $R$ 個の固有べクトルを取得 すれば良い 。

最後に , オブジェクトのある組み合わせ

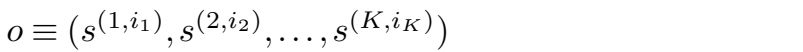
ブジェクトの埋め込み先 $\left[\boldsymbol{f}^{(k)}\right]_{i_{k}}$ と，光の組み合わせの 最適な埋め込み先 $\overline{\boldsymbol{f}}$ の間にも式 (3) は成立するので，o の最適な埋め込み先の $r$ 番目の次元は

$$
\frac{1}{K} \sum_{k=1}^{K}\left[\boldsymbol{f}_{r}^{(k)}\right]_{i_{k}}
$$

で与えられる．また，式(1)で定義したように，オブジェ クトと関係インスタンスの間のユークリッド距離が小さ いほど，光のオブジェクトと関係インスタンスの間に関 係が生じやすいので, 関係oは，

$$
\operatorname{diff}(o) \equiv \sum_{r=1}^{R} \sum_{k=1}^{K}\left(\left[\boldsymbol{f}_{r}^{(k)}\right]_{i_{k}}-\frac{1}{K} \sum_{k^{\prime}=1}^{K}\left[\boldsymbol{f}_{r}^{\left(k^{\prime}\right)}\right]_{i_{k^{\prime}}}\right)^{2} .
$$

の值が小さいほど生じやすいと考えられる.ゆえに，O に含まれない組み合わせ $o$ に対して , 関係の生じやすさ を表すスコア score (o) は $\operatorname{score}(o) \equiv-\operatorname{diff}(o)$ などとして与えられる .

非凸な目的関数を持つ当初の最適化問題 (5) が一般化 固有値問題に帰着されたことは特筆すべきである．一般 化固有値問題は厳密に解くことができるため, 当初の最 適化問題に対して大域解を得ることが可能になる．この 性質は，局所解のみ保証する既存の多くのテンソル分解 手法と対照的である.更に ，既存の多くの手法 [Kolda 09] では, 複数の固有值問題を解かなければならない一方, 提 案手法では一般化固有値問題を一度解くだけで大域解が 求まる。 


\section{$2 \cdot 3$ オブジェクトの属性の活用}

続いて , オブジェクトの属性情報 $\left\{\boldsymbol{\Phi}^{(k)}\right\}_{k=1}^{K}$ を統合す ることを考える.オブジェクトの属性を活用することは， 僅かな関係にしか参加しないようなオブジェクトが存在 する場合や，予測を，訓練段階では未観測であったオブ ジェクトに対して行う必要がある場合などにおいて特に 重要となる。

線形写像

$$
\boldsymbol{f}^{(k)} \equiv \boldsymbol{\Phi}^{(k)} \boldsymbol{w}^{(k)},
$$

を考える .ここで, $\boldsymbol{w}^{(k)}$ は $D^{(k)}$ 次元の属性ベクトルを 一次元の潜在空間に写像する $D^{(k)}$ 次元のパラメータで ある

属性情報を活用しない場合と同樣にラグランジュ関数 を定義し，乥れを最適化することで，

$$
\begin{aligned}
\sum_{\ell} \boldsymbol{\Phi}^{(k)^{\top}} \boldsymbol{A}^{(k)} \boldsymbol{A}^{(\ell)^{\top}} \boldsymbol{\Phi}^{(\ell)} \boldsymbol{w}^{(\ell)} & \\
= & K(\lambda+1) \boldsymbol{\Phi}^{(k)^{\top}} \boldsymbol{D}^{(k)} \boldsymbol{\Phi}^{(k)} \boldsymbol{w}^{(k)},
\end{aligned}
$$

を得ることができる.これは以下の一般化固有値問題と して表現できる .

$$
\boldsymbol{\Phi}^{\top} \boldsymbol{A} \boldsymbol{A}^{\top} \boldsymbol{\Phi} \boldsymbol{w}=\tilde{\lambda} \boldsymbol{\Phi}^{\top} \boldsymbol{D} \boldsymbol{\Phi} \boldsymbol{w}
$$

ここで，

$$
\begin{aligned}
\boldsymbol{\Phi} & \equiv\left[\begin{array}{ccc}
\boldsymbol{\Phi}^{(1)} & & \mathbf{0} \\
& \ddots & \\
\mathbf{0} & & \boldsymbol{\Phi}^{(K)}
\end{array}\right] \\
\boldsymbol{w} & \equiv\left(\boldsymbol{w}^{(1)^{\top}}, \boldsymbol{w}^{(2)^{\top}}, \ldots, \boldsymbol{w}^{(K)^{\top}}\right)^{\top} .
\end{aligned}
$$

である . 属性べクトルの次元が高い場合 , 次元の呪い と呼ばれる効果により予測性能がしばしば悪化する．こ れを避けるため，正の值である正則化パラメータ $\sigma>0$ により，正則化項を追加するのが一般的である .この場 合 , 我々の一般化固有値問題 (11) は以下のように修正さ れる。

$$
\boldsymbol{\Phi}^{\top} \boldsymbol{A} \boldsymbol{A}^{\top} \boldsymbol{\Phi} \boldsymbol{w}=\lambda\left(\boldsymbol{\Phi}^{\top} \boldsymbol{D} \boldsymbol{\Phi}+\sigma \boldsymbol{I}\right) \boldsymbol{w} .
$$

\section{$2 \cdot 4$ 計算量について}

提案手法の処理は, 一般化固有値問題を解きオブジェ クトの潜在次元表現を得る次元削減部分と，弚の潜在次 元を用いた予測部分の二つに分けられる . 前者について は，属性を考慮した式 (12)で $\Phi$ を単位行列として $\sigma=$ 0 とおけば式 (7) になるので, 式 (12) について述べる と, この計算量は $B=\boldsymbol{\Phi}^{\top} \boldsymbol{A} A^{\top} \boldsymbol{\Phi}, \boldsymbol{C}=\boldsymbol{\Phi}^{\top} \boldsymbol{D} \boldsymbol{\Phi}+\sigma \boldsymbol{I}$ とおいたときの一般化固有値問題 $\boldsymbol{B} \boldsymbol{x}=\lambda \boldsymbol{C} \boldsymbol{x}$ の計算量 に相当する．今， $C$ は正定値対称行列であり，原理的に $\boldsymbol{C}^{-1} \boldsymbol{B} \boldsymbol{x}=\lambda \boldsymbol{x}$ と固有值問題に帰着できるが, 本論文で は $\boldsymbol{C}=\boldsymbol{L} \boldsymbol{L}^{T}$ ( $\boldsymbol{L}$ は下三角行列 $)$ と $\boldsymbol{C}$ をコレスキー分
解し, $\boldsymbol{F} \boldsymbol{y}=\lambda \boldsymbol{y},\left(\boldsymbol{F}=\boldsymbol{L}^{-1} \boldsymbol{B} \boldsymbol{L}^{-T}, \boldsymbol{y}=\boldsymbol{L}^{T} \boldsymbol{x}\right)$ という固 有値問題に帰着させる. $\boldsymbol{B}, \boldsymbol{C}$ を $n * n$ の行列とすると， $\boldsymbol{C}$ のコレスキー分解と $\boldsymbol{L}, \boldsymbol{L}^{T}$ の逆行列化の計算量は, 並 列化なしの場合はいずれも $O\left(n^{3}\right)$ だが，並列化によっ て兴れ光れ $O\left(\log ^{3} n\right), O\left(\log ^{2} n\right)$ となる [Csanky 76, Pan 87] . 帰着された固有値問題 $\boldsymbol{F} \boldsymbol{y}=\lambda \boldsymbol{y}$ においては, $\boldsymbol{F}$ は対称行列なので, Implicitly Restarted Lanczos Method (IRLM)[Lehoucq 96, Sorensen 92] を用いて固有值問題を 解くことができ，この計算量は $O\left(m R h+n R^{2} h\right)($ ここ

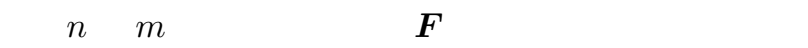
ド数とエッジ数, $h$ は IRLM が収束するまでのイテレー ション回数, $R$ は潜在次元数) となる [White 05]. これ

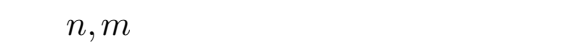

ある関係インスタンスが与えられたときにスコアを付 与する計算量は, 式 (9) の計算量として $O(K)$ ( $K$ は項数) となる (次元数 $R$ に関する和を取る部分はべクトルとし て表記可能なため) . オブジェクトの全組み合わせに対 して式 (9) を計算するには, 現状では全組み合わせを列 挙するため $O\left(\sqcap_{k=1}^{K} N^{(k)}\right)$ となる.ここで, $N^{(k)}$ は， $k$ 種類目のオブジェクトのオブジェクト数である . 実用的 には，スコアの高いもの上位 $l$ 個について兴の組み合わ せとスコアを得られれば十分な場合も想定される . 弚の ようなアプリケーションに応じた対応も含め, 計算量の 削減か課題となる。

\section{3. 実験}

ここでは, ソーシャルメディア上でのユーザーの行動 予測を応用として，提案手法がデータ踈性に対する高い 頑健性を持つことを，現実の三種類のデータセットを用 いた実験によって示す．

\section{$3 \cdot 1$ 応用事例: ソーシャルメディア上でのユーザの行動} 予測

Facebookや Twitter ,Tumblrなどに代表されるソーシャ ル Web サービスは, 検索サービスと並び, World Wide Web の主要な利用の場として普及した .ソーシャル Web サービスにおける重要なコンセプトの一つはユーザの行 動である . 例えば , ユーザは, ソーシャルブックマーク サービスを使い, Web ページ, 写真, 論文などの樣々なリ ソースに対してキーワードを付与することができ，更に光 れを他のユーザと共有することができる .ユーザはまた ， Twitter における “retweet”や Tumblr における “reblog”な どの機能を通じて，他のユーザーが発信した情報を，自 身のソーシャルネットワークを介して他のユーザに再発 信することができる．近年，これらの行為データをWeb における推薦や，個人化された検索などの樣々なタスク に活用する試みが盛んに行われている．例えば，ユーザ のタグ付けデータは, 検索 [Bao 07, Heymann 08] , 人間 関係の推論 [Schifanella 10] , オントロジーの発見 [Mika 
05]などのタスクに有用であることが示されている.更 に，ユーザの行動自体の予測が可能になると炎の応用可 能性は一段と広がる .一例として , ソーシャルブックマー クサービス上でユーザが各リソースに対して付与できる タグを推薦する，タグ推薦のタスクが挙げられる．タグ 推薦の機能によって, より多くのユーザがより多くのリ ソースに対してタグを付与するようになることで, リソー スに付随する情報を増やすことができ，情報抽出の質を 向上させることができる [Guan 09] と期待できる . 本実 験では, deli.cio.us と呼ばれるソーシャルブックマーク 上でのタグ付け行為と，マイクロブログサービス Twitter 上でのユーザーのいくつかの行為を対象として, 光の行 動予測を行う . データの詳細は以下で述べる .

\section{$3 \cdot 2$ データ セット}

表 1 に，使用した三つのデータセットについて詳細を 記載した . 最初の二つのデータセット ${ }^{* 2}$ は , マイクロブ ログサービス Twitter から取得したものであり，ここで は“retweet”と“favorite”という二つの行為を対象とした . 各行為は, 行為主体ユーザ (subjective user), 発信元ユー ザ (mentioned user)，URL という，三種類のオブジェク 卜から構成されるタプルとして表現できる . 各タプルに より表現されているのは, 発信元ユーザの tweet によっ て投稿された URL に対して，行為主体ユーザか特定の行 為 (retweet/favorite) を行ったということである.三つ 目のデータセット ${ }^{3}$ は del.icio.us というソーシャルタギ ングサービスから取得したものであり, 各行為は, ユー ザ (user)，ユーザによって付与されたタグ (tag)，URLか ら成るタプルで表現される. 提案手法では, 関係データ の他に表 1 に示されるような各オブジェクトの属性も活 用した . 詳細は表 1 にまとめられている. 特徵べクトル を構築する際には TF-IDF を用い，属性值が $[0.0,1.0]$ の 範囲に収まるようにした . deli.cio.us における “friend 関 係にあるユーザ”の属性以外は, 各オブジェクトについて TF-IDF 值が上位 5 つの属性值を持つ属性を活用した .

\section{$3 \cdot 3$ 実験設定: 関係レベルで疎な状況とオブジェクトレ ベルで疎な状況}

実験条件として，導入で述べた，多項関係予測におい て問題となる二種類の疎な状況，すなわち, 関係レベル で疎である状況とオブジェクトレベルで疎である状況を 設定した . 関係レベルで疎な設定は，いくつかの関係イ ンスタンスがランダムに欠けている状況を仮定する．才 ブジェクトレベルで疎な設定は, 特定のオブジェクトを 含む全ての関係インスタンスが欠けている状況を仮定す る. 後者の疎な状況は, 推薦システムにおけるコールド スタート問題として知られている。例えば，新しいユー

*2 http://norizm.org/datasets.html

*3 http://www.grouplens.org/node/462\#

attachments
ザが初めてオンラインショッピングのサイトに訪れた時， 大抵の場合，弚のユーザに関して得られる情報はほとん ど，もしくは全くない．このため, 弚のユーザに対して 何らかの行動予測を行うことは難しい .

関係レベルで踈な設定では, 全データセットから，観 測された関係インスタンスの一定割合をランダムにサン プリングし訓練データとして用い, 残りのデータを評価 データとした .オブジェクトレベルで疎な設定では , 観測 されたオブジェクトの一定割合をランダムにサンプリン グし，光のオブジェクトを含まなかった関係インスタン スを訓練データとして用いた．残りのデータは評価デー

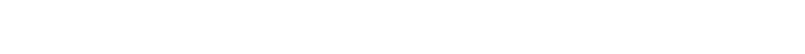
比率を変え, 各サンプリング比率について, サンプリン グ, 予測, 評価の一連のプロセス (以降, この一連のプ ロセスをスロットと呼ぶ） 10 回繰り返した . 予測性能 の評価指標としては AUC を用いた . AUC は, 評価デー タの中で, 未観測の関係インスタンスのリンク強度より も，観測済みの関係インスタンスのリンク強度が高い値 となる確率として計算できる．

\section{4 比較 手 法}

比較手法としては, CP 分解 (PARAFAC) と, Tucker 分解と呼ばれる二つの標準的なテンソル分解の手法を採 用した. CP 分解/Tucker 分解は, 元のテンソルと, 近似 したテンソルの間に定義した距離を最小化する最適化問 題として定式化される. $\mathrm{CP}$ 分解は, テンソルをランク 1 のテンソルの和として近似するものであり，Tucker 分解 は, テンソルをコアテンソルといくつかの因子行列を用い て近似する. $\mathrm{CP}$ 分解では, 三階テンソル $\mathcal{X} \in \mathbb{R}^{I \times J \times K}$ が与えられた時 , このテンソルは $\mathcal{X} \approx \sum_{r=1}^{R} \mathbf{a}_{\mathbf{r}} \circ \mathbf{b}_{\mathbf{r}} \circ \mathbf{c}_{\mathbf{r}}$ によって近似される.ここで, $r=1, \ldots, R$ につて $\mathbf{a}_{\mathbf{r}} \in$ $\mathbb{R}^{I}, \mathbf{b}_{\mathbf{r}} \in \mathbb{R}^{J}, \mathbf{c}_{\mathbf{r}} \in \mathbb{R}^{K}$ であり,。は外積を表す. $\mathcal{X}$ の各要 素 $[\mathcal{X}]_{i, j, k}$ は $, i=1, \ldots, I, j=1, \ldots, J, k=1, \ldots, K$ に ついて $[\boldsymbol{\mathcal { X }}]_{i, j, k} \approx \sum_{r=1}^{R}\left[\mathbf{a}_{\mathbf{r}}\right]_{i}\left[\mathbf{b}_{\mathbf{r}}\right]_{j}\left[\mathbf{c}_{\mathbf{r}}\right]_{k}$ として近似される. Tucker 分解では, $\mathcal{X}$ の各要素 $[\mathcal{X}]_{i, j, k}$ は,

$[\boldsymbol{X}]_{i, j, k} \approx \sum_{p=1}^{P} \sum_{q=1}^{Q} \sum_{r=1}^{R}[\mathcal{G}]_{p, q, r}[\mathbf{A}]_{i, p}[\mathbf{B}]_{j, q}[\mathbf{C}]_{k, r}$ によって近似される. $\mathcal{G} \in \mathbb{R}^{P \times Q \times R}$ はコアテンソル， $\mathbf{A} \in \mathbb{R}^{I \times P}, \mathbf{B} \in \mathbb{R}^{J \times Q}, \mathbf{C} \in \mathbb{R}^{K \times R}$ は因子行列である.詳 細は Kolda と Bader による解説 [Kolda 09] に詳しい . 本 実験ではTensorToolbox ${ }^{* 4}$ を用いた。

\section{$3 \cdot 5$ パラメー夕設定}

提案手法, 比較手法光れについて, 各サンプリン グ比率について，上記で定義した 1 スロットをチューニ ング用データして用い，AUC の観点からパラメータを 設定した .チューニングの際の結果は, 実際の実験結果 には含まれない，属性を活用しない提案手法では， $R$ は $\left\{2^{3}, 2^{4}, \ldots, 2^{9}\right\}$ の 7 つを，属性を活用する提案手法では，

\footnotetext{
*4 http://www.sandia.gov/ tgkolda/

TensorToolbox/index-2.3.html
} 


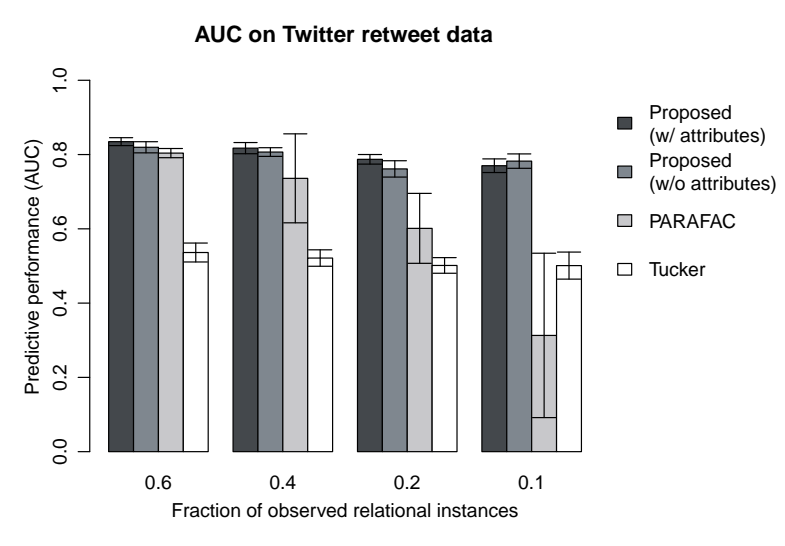

(a) Twitter における retweet アクション

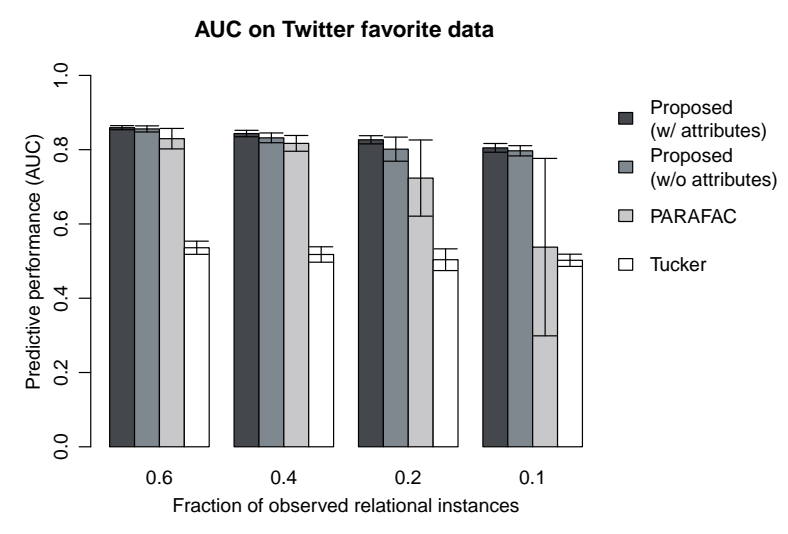

(b) Twitter における favorite アクション

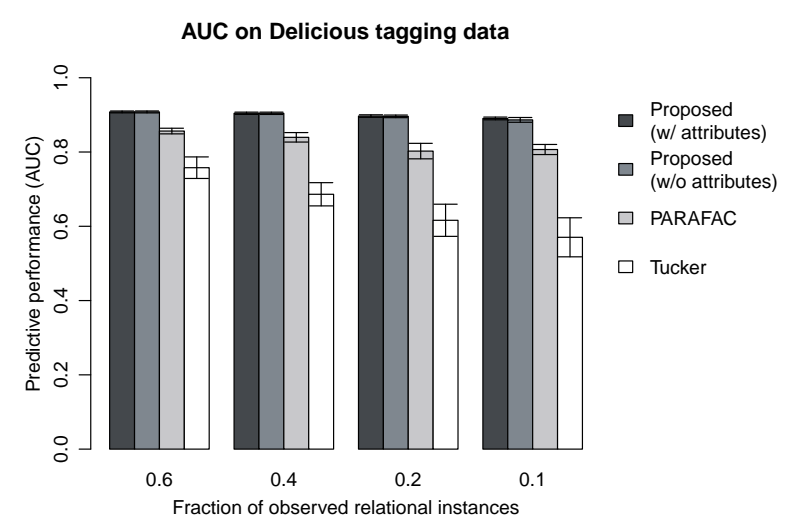

(c) Delicious における tagging アクション

図 2 関係レベルで踈な状況での AUC の比較 . 属性の活用の有無 に関わらず，提案手法がデータ踈性に対して最も高い頑強性 を示した。

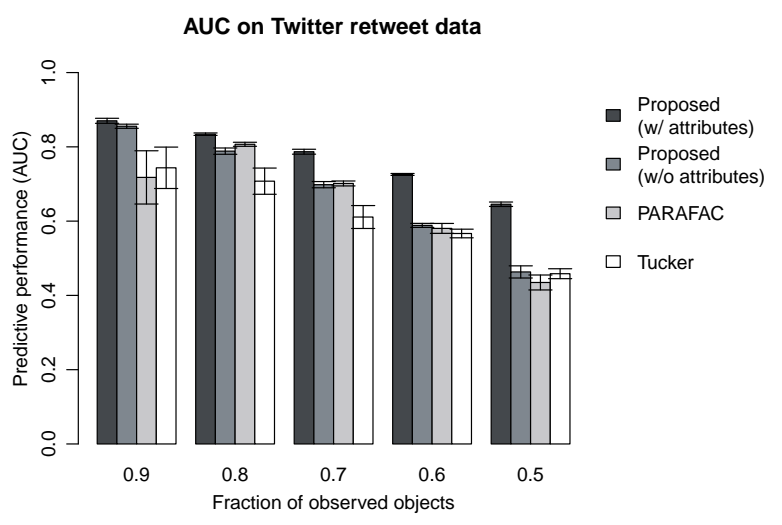

(a) Twitter における retweet アクション

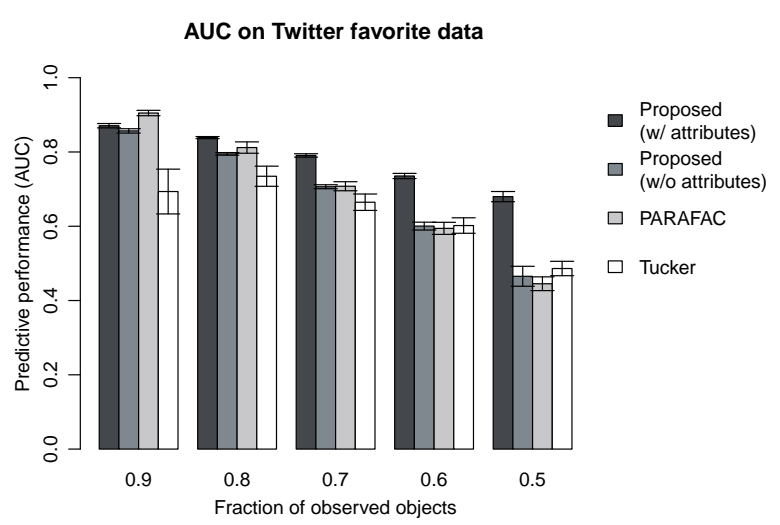

(b) Twitter における favorite アクション

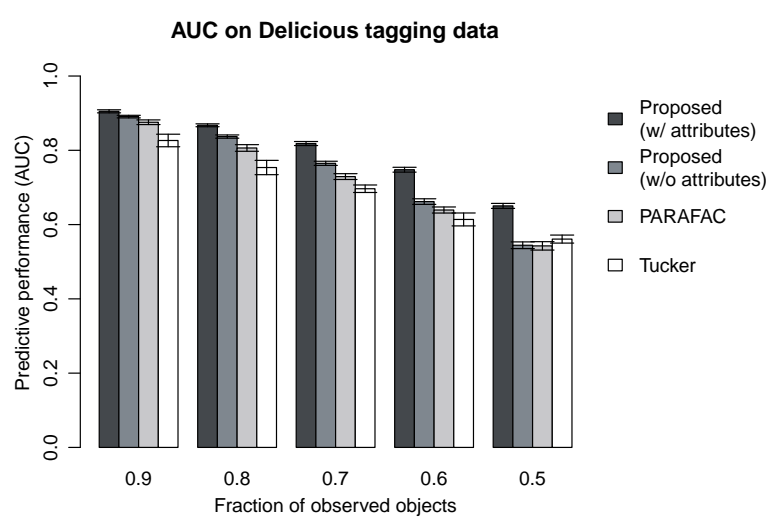

(c) Delicious における tagging アクション

図 3 オブジェクトレベルで疎な状況での AUC の比較 . 属性を活用 した提案手法がデータ疎性に対して最も高い頑強性を示した。 
$R$ は $\left\{2^{6}, 2^{7}, \ldots, 2^{9}\right\}$ のつを候補とした . 提案手法で属 性を活用する場合の $\sigma$ は $\left\{10^{-2}, 10^{-3}, 10^{-4}\right\}$ で評価した が このパラメータの範囲において安定した精度が確認 されたため，実際の実験では，10-3 で固定した . 比較手 法においては $R$ は, $\left\{2^{0}, 2^{1}, \ldots, 2^{4}\right\}$ のつを候補とした .

\section{$3 \cdot 6$ 結果}

提案手法は，関係レベルで疎な状況では，属性の活用 の有無に関わらず比較手法よりもデータ過疎に対して頑 強な性能を示した . オブジェクトレベルで踈な状況では 属性の活用か俲果を発揮し，属性を活用した提案手法は 比較手法よりも頑強な性能を示した。

図 2 か関係レベルで疎な設定での実験結果である.観 測された関係インスタンスの割合を $0.6,0.4,0.2,0.1$ と変 えたときの AUC の平均を，標準偏差付きで示してある . この割合が 0.6 である場合というのは, 全データセット の中で 6 割の関係インスタンスが訓練時に観測された場 合を指す．全データセットにおいて，属性の有無に関わ らず提案手法がデータ過疎への最も高い頑強性を示して いることが確認できる . 提案手法が見せている相対的に 小さい標準偏差は，大域解を保証する定式化によるもの と考えられる.詳細な分析として, 各手法の全ペアにつ いて $\mathrm{t}$ 検定 $(p<0.05)$ を行い以下の結論を得た . (1) 提 案手法において属性の有無による精度の有意差は必ずし もなかった .データセットやサンプリング比率によって， 属性の有無による有意差があるものとないものがあつた . (2) 観測された関係インスタンスの割合が 4 割以下の全 ての場合 (6 割以外の場合) には，属性の有無に関わら ず提案手法の比較手法に対する精度向上は有意であった． (3) 観測された関係インスタンスの割合が 6 割の場合は , 提案手法 (属性ありなし両方) の精度が比較手法の精度 を有意に上回るか，両者の間に有意差がないかのいずれ かであつた . (1)について, 提案手法において属性の活用 の有無による有意差が必ずしも見られない理由としては， オブジェクトか既知である場合には，属性情報よりも関 係データ关れ自身の情報か関係形成において支配的にな ることが考えられる．(2)，(3)について，提案手法が属 性の有無に関わらず, 比較手法に対してデータ過疎への 高い頑強性を示したのは，大域解を保証する定式化によ るものと考えられる .

图 3 がオブジェクトレベルで疎な設定での実験結果で ある. 予測時に既知であるオブジェクトの割合を

$0.9,0.8,0.7,0.6,0.5$ と変えたときの AUC の平均を, 標 準偏差付きで示してある .この割合が 9 割である場合と いうのは , 全オブジェクトの中で 1 割のオブジェクトが , 予測時に新しく観測された場合を指す.提案手法のうち属 性を活用していない方の手法は, 比較手法と同樣にデー 夕過踈に対して低い頑健性を示しているが，属性を活用 した提案手法はデータ過疎に対して相対的に高い頑強性 を示した . 関係レベルで疎な設定と同樣に，詳細な分析
として , 各手法の全ペアについて $\mathrm{t}$ 検定 $(p<0.05)$ を行 い以下の結論を得た . (1) 全ての場合で, 属性を活用した 提案手法の精度が , 活用しない提案手法の精度を有意に 上回った . (2) 既知のオブジェクトが 8 割以下の全ての場 合 (9割以外の場合)，すなわち未知のオブジェクトが 2 割以上存在する場合には，属性を活用した提案手法の精 度がテンソルを用いた比較手法の精度を有意に上回った． (3) 既知のオブジェクトが 9 割の場合には，提案手法の精 度がテンソルを用いた比較手法を有意に上回るか, 両者 の間に有意差がないかのいずれかであった . 属性を活用 した提案手法が比較手法に対してデータ過疎への高い頑 強性を示したのは, 未知のオブジェクトが多数存在する ような状況では，属性の活用が有効であったためと考え られる.この結果は，属性の活用がコールドスタート問 題を解決するにあたって有用であることを示唆している.

\section{4. 関 連 研 究}

多項関係予測においては,テンソルを用いた手法がよく 使用されている [Dunlavy 11, Koutra 12, Sun 06a, Kolda 05, Sun 06b, Symeonidis 08, Rendle 09, Rendle 10]. これ ら , テンソル補完問題等のテンソル分析タスクにおいて は，対象となるテンソルに対して低ランク性を仮定する ことが多く，樣々な低ランク分解モデルが，効率的なア ルゴリズムと共に提案されてきている [Kolda 09] . しか しながら，多くの既存手法で保証されるのは局所解のみ であり，光の予測性能は対象アルゴリズムに与える初期 值に大きく依存する.対照的に，提案手法では一般化固 有值問題を一度解くだけで大域解を得ることが可能にな る.このような性質と属性情報の統合により，提案手法 はデータ過疎に対して頑強な予測性能を実現した .

\section{5. おわりに}

本論文では, 異種のオブジェクト間に生じる多項関係 を予測するために , 関係データと, オブジェクトの属性 情報の両方を活用する手法を提案した . 提案手法は , 大 域解を保証する定式化とオブジェクトの属性を活用する 定式化により，標準的なテンソル分解と比較してデータ 過疎への高い頑強性を示した 。

\section{$\diamond$ 参 考 文 献 $\diamond$}

[Bao 07] Bao, S., Xue, G., Wu, X., Yu, Y., Fei, B., and Su, Z.: Optimizing web search using social annotations, in Proceedings of the 16th International Conference on World Wide Web, pp. 501-510 (2007)

[Belkin 03] Belkin, M. and Niyogi, P.: Laplacian Eigenmaps for Dimensionality Reduction and Data Representation, Neural Computation, Vol. 15, No. 6, pp. 1373-1396 (2003)

[Cai 11] Cai, Y., Zhang, M., Luo, D., Ding, C., and Chakravarthy, S.: Low-order tensor decompositions for social tagging recommendation, in Proceedings of the fourth ACM International Conference on 
表 1 実験で用いたデータセットの詳細

\begin{tabular}{|c|c|c|c|c|c|}
\hline データセット & タプル数 & オブジェクト & オブジェクト数 & 属性 & 属性数 \\
\hline Twitter & 14,221 & subjective user & 1,144 & ユーザの tweet に含まれるキーワード & 4,896 \\
& & mentioned user & 7,935 & follow されているユーザ & 2,586 \\
(retweet) & & URL & 11,335 & URL と共起した subjective user の tweet に含まれるキーワード & 4,757 \\
\hline Twitter & 22,755 & subjective user & 1,125 & ユーザの tweet に含まれるキーワード & 4,107 \\
& & mentioned user & 10,049 & follow されているユーザ & 2,586 \\
(favorite) & & URL & 18,244 & URL と共起した subjective user の tweet に含まれるキーワード & 4,107 \\
\hline Delicious & \multirow{2}{*}{33,414} & user & 768 & friend 関係にあるユーザ & 1,098 \\
& & tag & 8,280 & URL と共起したタグ & 15,088 \\
(tagging) & & URL & 6,860 & URL と共起したユーザ & 1,185 \\
\hline
\end{tabular}

Web Search and Data Mining, pp. 695-704 (2011)

[Csanky 76] Csanky, L.: Fast Parallel Matrix Inversion Algorithms, SIAM Journal on Computing, Vol. 5, No. 4, pp. 618-623 (1976)

[Dunlavy 11] Dunlavy, D. M., Kolda, T. G., and Acar, E.: Temporal Link Prediction Using Matrix and Tensor Factorizations, ACM Transactions on Knowledge Discovery from Data, Vol. 5, No. 2, pp. 10:1-10:27 (2011)

[Guan 09] Guan, Z., Bu, J., Mei, Q., Chen, C., and Wang, C.: Personalized tag recommendation using graph-based ranking on multi-type interrelated objects, in Proceedings of the 32nd Annual International ACM SIGIR Conference on Research and Development in Information Retrieval, pp. 540-547 (2009)

[Heymann 08] Heymann, P., Koutrika, G., and Garcia-Molina, H.: Can social bookmarking improve web search?, in Proceedings of the first International Conference on Web Search and Web Data Mining, pp. 195-206 (2008)

[Kolda 05] Kolda, T. G., Bader, B. W., and Kenny, J. P.: Higher-order web link analysis using multilinear algebra, in Proceedings of the fifth IEEE International Conference on Data Mining, pp. 242-249, IEEE Computer Society (2005)

[Kolda 09] Kolda, T. G. and Bader, B. W.: Tensor Decompositions and Applications, SIAM Review, Vol. 51, No. 3, pp. 455-500 (2009)

[Koutra 12] Koutra, D., Papalexakis, E. E., and Faloutsos, C.: TensorSplat: Spotting Latent Anomalies in Time, in Proceedings of the 16th Panhellenic Conference on Informatics, pp. 144-149 (2012)

[Lehoucq 96] Lehoucq, R. and Sorensen, D. C.: Deflation Techniques For An Implicitly Re-Started Arnoldi Iteration, SIAM Journal on Matrix Analysis and Applications, Vol. 17, pp. 789-821 (1996)

[Mika 05] Mika, P.: Ontologies Are Us: A Unified Model of Social Networks and Semantics, in Proceedings of the fourth International Semantic Web Conference, Vol. 3729, pp. 522-536, Springer (2005)

[Pan 87] Pan, V. Y.: Complexity of Parallel Matrix Computations, Theoretical Computer Science, Vol. 54, pp. 65-85 (1987)

[Rendle 09] Rendle, S., Balby Marinho, L., Nanopoulos, A., and Schmidt-Thieme, L.: Learning optimal ranking with tensor factorization for tag recommendation, in Proceedings of the 15th ACM SIGKDD international conference on Knowledge discovery and data mining, pp. 727-736 (2009)

[Rendle 10] Rendle, S. and Schmidt-Thieme, L.: Pairwise interaction tensor factorization for personalized tag recommendation, in Proceedings of the third ACM International Conference on Web Search and Data Mining, pp. 81-90 (2010)

[Schein 02] Schein, A. I., Popescul, A., Popescul, R., Ungar, L. H., and Pennock, D. M.: Methods and Metrics for Cold-Start Recommendations, in Proceedings of the 25th annual International ACM SIGIR Conference on Research and Development in Information Retrieval, pp. 253-260 (2002)

[Schifanella 10] Schifanella, R., Barrat, A., Cattuto, C., Markines, B., and Menczer, F.: Folks in Folksonomies: social link prediction from shared metadata, in Proceedings of the third ACM International Conference on Web Search and Data Mining, pp. 271-280 (2010)

[Sorensen 92] Sorensen, D. C.: Implicit application of polynomial filters in a k-step Arnoldi method, SIAM Journal on Matrix Analysis and Applications, Vol. 13, No. 1, pp. 357-385 (1992)

[Sun 06a] Sun, J., Papadimitriou, S., and Yu, P. S.: Window-based
Tensor Analysis on High-dimensional and Multi-aspect Streams, in Proceedings of the sixth IEEE International Conference on Data Mining, pp. 1076-1080 (2006)

[Sun 06b] Sun, J., Tao, D., and Faloutsos, C.: Beyond streams and graphs: dynamic tensor analysis, in Proceedings of the 12th ACM SIGKDD international conference on Knowledge discovery and data mining, pp. 374-383 (2006)

[Symeonidis 08] Symeonidis, P., Nanopoulos, A., and Manolopoulos, Y.: Tag recommendations based on tensor dimensionality reduction, in Proceedings of the 2nd ACM International Conference on Recommender Systems, pp. 43-50 (2008)

[Voloshin 09] Voloshin, V. I.: Introduction to Graph and Hypergraph Theory, Nova Kroshka Books (2009)

[White 05] White, S. and Smyth, P.: A spectral clustering approach to finding communities in graphs, in Proceedings of the fifth SIAM International Conference on Data Mining (2005)

[Yamanishi 09] Yamanishi, Y.: Supervised Bipartite Graph Inference, in Proceedings of the 23rd Annual Conference on Neural Information Processing Systems, pp. 1841-1848 (2009)

〔担当委員 : 小町 守〕

2013 年 7 月 23 日 受理

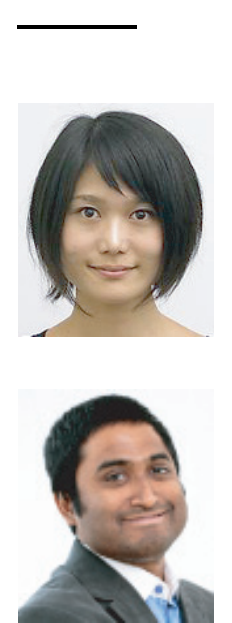

者 紹 介

\section{則のぞみ(学生会員)}

2010 年東京大学工学部システム創成学科卒. 2012 年東京 大学大学院情報理工学系研究科創造情報学専攻修士課程終 了. 広く情報学と社会学の接点に興味を持つ. 現在はグラ フ/ネットワーク解析, Web マイニング, 機械学習に関す る研究を行っている. ACM 会員.

\section{ボレガラ ダヌシカ(正会員)}

2005 年東京大学工学部電子情報工学科卒. 2007 年同大学 院情報理工学系研究科修士課程修了. 2009 年同研究科博士 課程修了. 博士 (情報理工学). 同研究科・助教, 講師を経 て現在は University of Liverpool (Department of Computer Science) の Senior Lecturer (Associate Professor) . 自然言 語処理に興味を持つ.WWW, ACL, ECAIなどの会議を中 心に研究成果を発表.

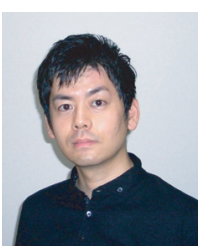

\section{鹿島 久嗣(正会員)}

1999 年京都大学大学院工学研究科応用システム科学専攻 修士課程修了. 2007 年京都大学大学院情報学研究科知能情 報学専攻博士課程修了. 博士 (情報学). 1999 年から 2009 年まで日本アイ・ビー・エム株式会社 東京基礎研究所勤務. 2009 年より東京大学大学院情報理工学系研究科数理情報 学専攻・准教授. 機械学習やデータマイニングの研究, 特に グラフやネットワーク構造をもったデータを対象とする予 測モデリングに取り組む 